\title{
Phosphoinositide 3-kinase $\delta$ inhibition promotes antitumor responses but antagonizes checkpoint inhibitors
}

\author{
Ee Lyn Lim, ${ }^{1}$ Fiorella M. Cugliandolo, ${ }^{1}$ Dalya R. Rosner, ${ }^{1}$ David Gyori, ${ }^{1}$ Rahul Roychoudhuri, ${ }^{1}$ \\ and Klaus Okkenhaug ${ }^{1,2}$ \\ 'Laboratory of Lymphocyte Signalling and Development, The Babraham Institute, Cambridge, United Kingdom. ${ }^{2}$ Division \\ of Immunology, Department of Pathology, University of Cambridge, Cambridge, United Kingdom.
}

\begin{abstract}
Multiple modes of immunosuppression restrain immune function within tumors. We previously reported that phosphoinositide 3-kinase $\delta(P I 3 K \delta)$ inactivation in mice confers resistance to a range of tumor models by disrupting immunosuppression mediated by regulatory $T$ cells (Tregs). The PI3K $\delta$ inhibitor idelalisib has proven highly effective in the clinical treatment of chronic lymphocytic leukemia and the potential to extend the use of PIЗK $\delta$ inhibitors to nonhematological cancers is being evaluated. In this work, we demonstrate that the antitumor effect of PI3K $\delta$ inactivation is primarily mediated through the disruption of Treg function, and correlates with tumor dependence on Treg immunosuppression. Compared with Treg-specific PI3K $\delta$ deletion, systemic PI3K $\delta$ inactivation is less effective at conferring resistance to tumors. We show that PI3K $\delta$ deficiency impairs the maturation and reduces the capacity of CD8+ cytotoxic T lymphocytes (CTLs) to kill tumor cells in vitro, and to respond to tumor antigen-specific immunization in vivo. PI3K $\delta$ inactivation antagonized the antitumor effects of tumor vaccines and checkpoint blockade therapies intended to boost the $\mathrm{CD8}^{+} \mathrm{T}$ cell response. These findings provide insights into mechanisms by which $\mathrm{PI} 3 \mathrm{~K} \delta$ inhibition promotes antitumor immunity and demonstrate that the mechanism is distinct from that mediated by immune checkpoint blockade.
\end{abstract}

Conflict of interest: DG was funded by a grant from Karus Therapeutics Ltd. $K O$ has received consultancy fees from Karus Therapeutics and Gilead.

License: This work is licensed under the Creative Commons Attribution 4.0 International License. To view a copy of this license, visit http:// creativecommons.org/licenses/by/4.0/

Submitted: February 20, 2018

Accepted: May 1, 2018

Published: June 7, 2018

Reference information: JCI Insight. 2018;3(11):e120626. https://doi.org/10.1172/jci. insight.120626.

\section{Introduction}

Modulation of the immune response as a therapeutic strategy for cancer has proven to be a successful approach in some cancers. Studies using checkpoint blockade antibodies against cytotoxic T lymphocyte antigen 4 (CTLA-4) or the programmed death 1 (PD-1)/programmed death ligand 1 (PD-L1) axis have focused on the enhancement of $\mathrm{CD}^{+} \mathrm{T}$ cell activity (1-3). Anti-CTLA-4 antibody therapy has additionally been reported to deplete regulatory $\mathrm{T}$ cells (Tregs) in some contexts (4). We previously reported that inactivation of phosphoinositide 3-kinase $\delta(\mathrm{PI} 3 \mathrm{~K} \delta$ ), a central signaling component in leukocytes, conferred tumor resistance to a variety of tumor types, and that this protective effect could be explained by a key role for PI3K $\delta$ in Tregs (5). The PI3K $\delta$ pathway is engaged by the T cell receptor (TCR), the interleukin 2 (IL-2) receptor, and costimulatory receptors, and its inhibition could equally influence the effector immune response required for tumor clearance $(6,7)$. The challenge, therefore, is to define conditions that optimize the beneficial effect of PI3K $\delta$ inhibition on Tregs while minimizing adverse effects on effector $\mathrm{T}$ cell (Teff) populations during antitumor immune responses. The PI3K $\delta$ inhibitor idelalisib has recently been approved for the treatment of chronic lymphocytic leukemia (CLL) and follicular lymphoma $(8,9)$. In these B cell cancers, PI3K $\delta$ plays an important cell-intrinsic role, but may also affect cells in the tumor microenvironment $(10,11)$. To fully realize the potential of PI3K $\delta$ inhibitors and for the optimal design of patient stratification and combinatorial therapies, it is imperative to further elucidate the impact of PI3K $\delta$ inhibition on tumor immunity.

In this report, we show that the efficacy of $\mathrm{PI} 3 \mathrm{~K} \delta$ inactivation in restricting tumor growth correlates with the dependence of the specific tumor on Treg-mediated immunosuppression. Using ovalbumin-expressing (OVA-expressing) derivatives of cell lines to enable specific characterization of tumor antigen-specific CD8 ${ }^{+}$ $\mathrm{T}$ cells, we found that the EL4-OVA lymphoma and MC38-OVA colon carcinoma were impaired in growth upon both Treg depletion and Treg-specific PI3K $\delta$ deletion, but the Lewis lung carcinoma (LLC-OVA) was 
unaffected in either condition. However, MC38-OVA tumors showed no growth reduction in mice with systemic PI3K $\delta$ inactivation. We found that PI3K $\delta$-deficient $C D 8^{+} \mathrm{T}$ cells had defects in maturation and cytotoxicity in vitro, and were impaired in their response to Listeria monocytogenes immunization in vivo. Furthermore, anti-CTLA-4 and anti-PD-L1 treatments failed to synergize with, and were indeed antagonized by, the loss of PI3K $\delta$ function in host cells.

\section{Results}

Efficacy of PI3K $\delta$ deletion in restricting tumor growth correlates with tumor dependence on Treg-mediated immunosuppression. We sought to determine the dependence of the different tumor models on Treg-mediated immunosuppression by transiently depleting Tregs from tumor-bearing mice. For these experiments we used the following tumor lines expressing OVA as a model antigen: EL4-OVA, MC38-OVA, or LLC-OVA (see Supplemental Figure 1 for characterization of immune cell infiltrates in each of these tumors; supplemental material available online with this article; https://doi.org/10.1172/jci.insight.120626DS1). Foxp3 ${ }^{\text {DTR }}$ mice, along with C57BL/ 6 controls, were implanted with EL4-OVA, MC38-OVA, or LLC-OVA tumors; all mice were then treated with diphtheria toxin (DTx) on days 3, 7, and 10 after tumor injection. Administration of DTx reduced the proportion of $\mathrm{CD}^{+}{ }^{+}$Foxp $3^{+}$Tregs among splenic lymphocytes by $65 \% 24$ hours after injection, with near-complete recovery by 4 days after injection, i.e., prior to the next dose (Figure 1A).

Only in EL4-OVA tumors did we observe a significant reduction in Tregs after DTx administration, while LLC-OVA and MC38-OVA tumors showed no decrease at the time of tumor collection (Figure 1B). These differences may reflect the fact that the EL4-OVA tumors were collected 14 days after implantation, just 4 days after the last dose of DTx, whereas the LLC-OVA and MC38-OVA tumors were allowed to grow for 18 and 24 days, respectively, at which point Tregs were more likely to have recovered (12).

Nevertheless, transient Treg depletion led to reduced growth of EL4-OVA and MC38-OVA tumors, whereas LLC-OVA tumor growth was not affected (Figure 1C). These data indicated that Tregs were a nonredundant component of immunosuppression in EL4-OVA and MC38-OVA tumors, whereas LLC-OVA tumors likely relied on other factors to evade immune attack.

These results were mirrored in mice with a Treg-specific deletion of PI3K $\delta$ (Figure 1D). As has been previously reported with the parental tumor EL4 (5), FYC-PI3K $\delta^{\mathrm{fl}}$ mice showed much reduced growth of EL4-OVA tumors compared with WT or PI3K $\delta^{\mathrm{D} 910 \mathrm{~A}}$ mice (Figure $1 \mathrm{D}$ and Supplemental Figure 2). Similarly, FYC-PI3K $\delta^{\mathrm{fl}}$ mice were resistant to MC38-OVA tumors. By contrast, LLC-OVA tumors grew at the same rate in FYC-PI3K $\delta^{\text {fl }}$ mice compared with WT controls. The data confirm that the antitumor effect of PI3K $\delta$ deficiency is exerted through a loss of Treg suppressive function, in a manner that mimics Treg depletion, such that its efficacy correlates with the dependence of the tumor on Treg immunosuppression.

Systemic PI3K inactivation negates antitumor effect of Treg dysfunction in MC38-OVA tumors. In PI3K $\delta^{\mathrm{D} 910 \mathrm{~A}}$ mice, bearing a kinase-inactivating point mutation in PI3K $\delta$, EL4-OVA tumors were significantly restricted in growth, in a similar manner to mice with Treg-specific PI3K $\delta$ deletion (Figure 1E and Supplemental Figure 2). LLC-OVA tumors exhibited no difference in growth regardless of the systemic nature of PI3K $\delta$ inactivation. However, in contrast to Treg-specific deletion, systemic inhibition of PI3K $\delta$ did not result in reduced growth of MC38-OVA cells.

We determined that the unresponsiveness of MC38-OVA tumors to PI3K $\delta$ inactivation was not due to an imperviousness of MC38-OVA tumor-infiltrating Tregs to a loss of PI3K $\delta$ activity. Indeed, a decrease in infiltrating Tregs in PI3K $\delta$-deficient mice was observed only in MC38-OVA tumors, and not in EL4-OVA or LLC-OVA tumors (Figure $1 \mathrm{~F}$ ). This implies an additional effect of PI3K $\delta$ inactivation, which can negate the beneficial antitumor effects of PI3K $\delta$ loss in Tregs. We considered CD8 ${ }^{+} \mathrm{T}$ cells to be the most likely culprit.

In vitro cytotoxicity assay shows differential killing in different tumor cells, with a consistent reduction of cytotoxicity in PI3K $\delta^{D 910 A} C D 8^{+} T$ cells. As a functional test for $\mathrm{CD}^{+} \mathrm{T}$ cells under PI3K $\delta$ inactivation, a cytotoxicity assay was used to measure OT-I CD8 ${ }^{+} \mathrm{T}$ cell killing of tumor cells expressing the cognate antigen OVA (see Methods section for experimental setup). Figure 2A shows an example of the flow cytometric readout from this assay, showing, from left to right, a near-complete clearance of green (OVA-expressing) tumor cells by WT OT-I CD $8^{+} \mathrm{T}$ cells, a moderate reduction of green cells by PI3K $\delta^{\mathrm{D} 910 \mathrm{~A}} \mathrm{OT}-\mathrm{I} \mathrm{CD} 8^{+} \mathrm{T}$ cells, and the original ratio of green and orange (parental) cells incubated without $\mathrm{CD} 8^{+} \mathrm{T}$ cells.

WT OT-I CD $8^{+} \mathrm{T}$ cells showed greater cytotoxic efficiency than PI3K $\delta$-inactivated OT-I CD $8^{+} \mathrm{T}$ cells in assays with EL4-OVA/EL4 cells (consistent with previous results), MC38-OVA/MC38 cells, or LLCOVA/LLC cells (Figure 2B). While PI3K $\delta^{\text {D910A }}$ OT-I CD8 ${ }^{+} \mathrm{T}$ cells were less effective than WT OT-I cells 
A

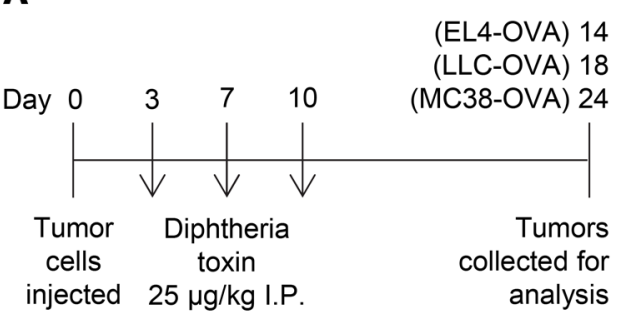

$\mathrm{CD}^{+} \mathrm{Foxp}^{+}$

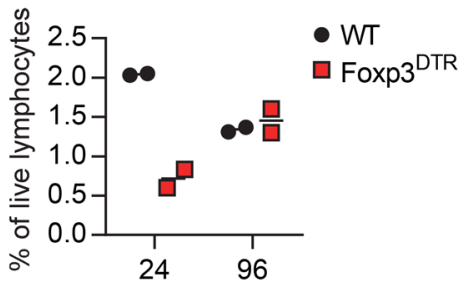

Hours post-DTx treatment
B

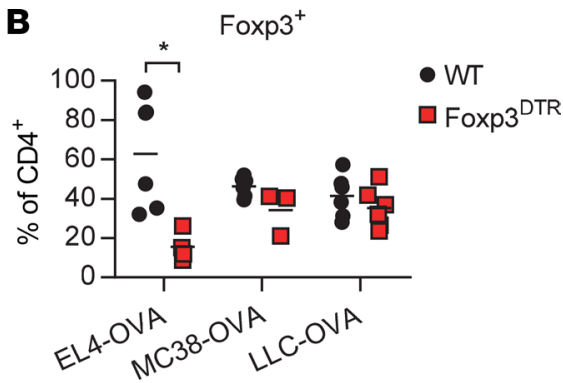

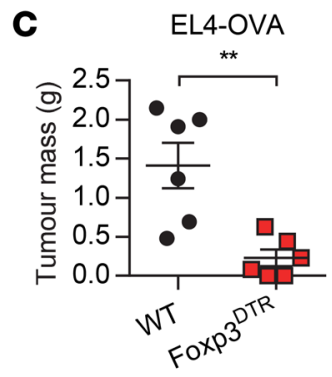
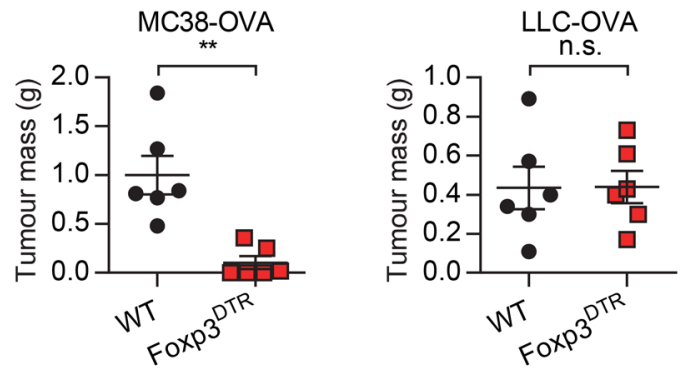

D

EL4-OVA
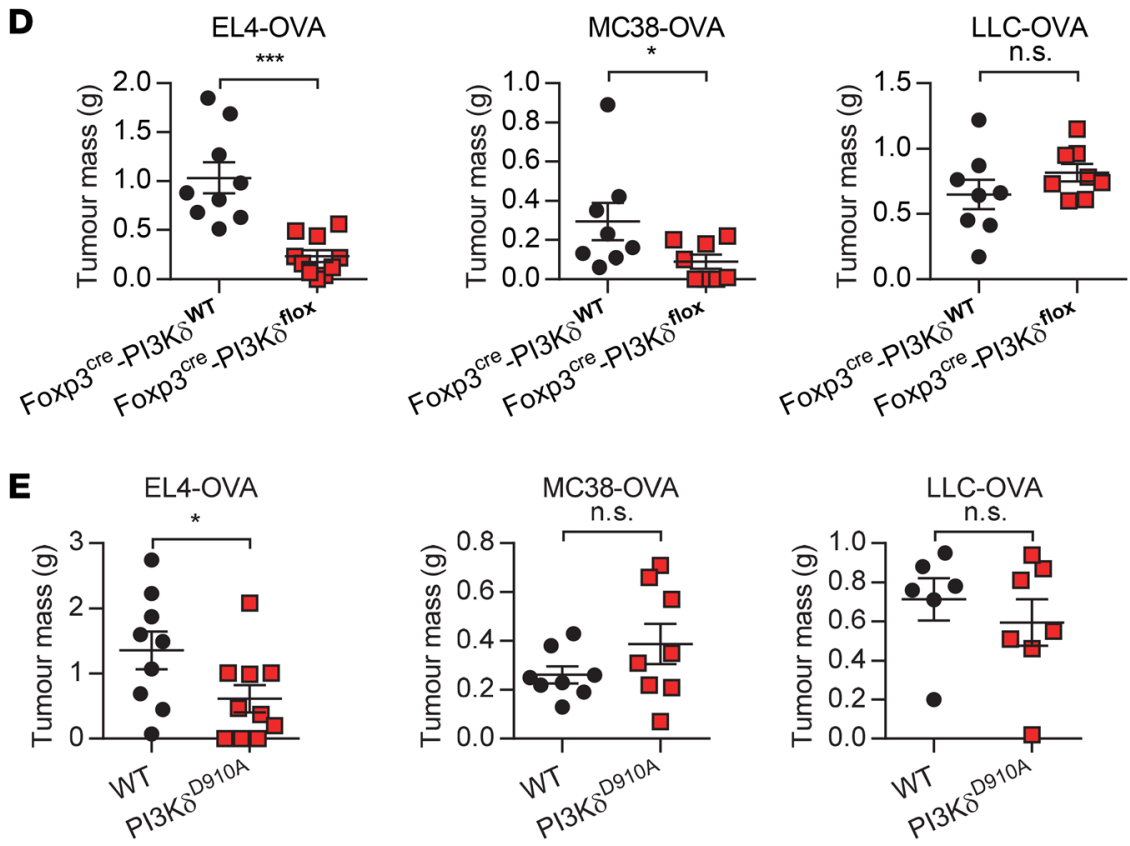

$\mathbf{F}$

Foxp3 $^{+}$
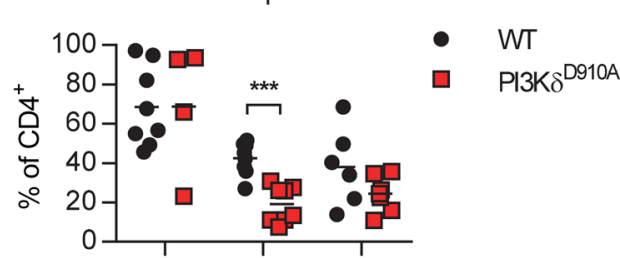

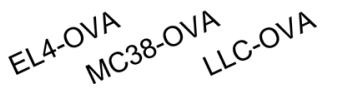

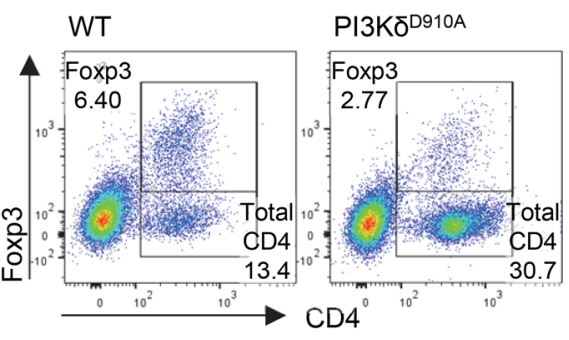

Figure 1. Deletion of phosphoinositide 3-kinase $\delta(P I 3 K \delta$ ) in regulatory T cells (Tregs) mimics the effects of Treg depletion, but systemic PI3K $\delta$ inactivation is less effective. (A) Diphtheria toxin (DTx) was administered i.p. on days 3, 7, and 10 after s.c. tumor injection into the flank on day 0 $(n=6)$. EL4-OVA, MC38-OVA, and LLC-OVA tumors were removed on days 14, 24, and 18 after implantation, respectively. Proportions of Tregs in the blood of non-tumor-bearing mice $(n=2)$ were measured 24 hours after administration, and again immediately before the subsequent dose. (B) Proportion of tumor-infiltrating Tregs in the EL4-OVA, MC38-OVA, and LLC-OVA tumors at the time of collection. (C) Masses of EL4-OVA, MC38-OVA, and LLC-OVA tumors removed from WT or Foxp $3^{\text {TTR }}$ mice as described in A. (D) Masses of EL4-OVA, MC38-OVA, and LLC-OVA tumors removed from 
WT or Foxp3 ${ }^{\text {cre }}$-PI3K $\delta^{\text {fl }}$ mice. (E) Masses of EL4-OVA $(n=10)$, MC38-OVA $(n=8)$, and LLC-OVA $(n=8)$ tumors in WT or PI3K $\delta^{\text {D910A }}$ mice. (F) Proportion

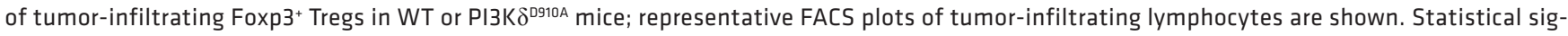
nificance was determined by multiple $t$ tests with Holm-Sidak correction (B and $\mathbf{F}$ ) or Mann-Whitney test $(\mathbf{C}, \mathbf{D}$, and $\mathbf{E}) .{ }^{*} P<0.05 ;{ }^{*} P<0.01 ;{ }^{* *} P<$ 0.001. n.s., not significant.

in eliminating target cells, they were nonetheless capable of a substantial amount of cell killing, especially when provided with EL4-OVA targets. Both WT and PI3K $\delta^{\mathrm{D} 910 \mathrm{~A}}$ OT-I CD8 ${ }^{+} \mathrm{T}$ cells were less efficient at killing MC38-OVA cells than EL4-OVA cells, and were least efficient at eliminating LLC-OVA cells.

The influence of target antigen affinity on OT-I CD $8^{+} \mathrm{T}$ cell cytotoxicity was tested with a panel of SIINFEKL peptide variants, modified from the native peptide to give varying binding affinities for the OT-I TCR (13). EL4 cells were pulsed with $10 \mathrm{nM}$ SIINFEKL or its variants (SAINFEKL, A2; SIIQFEKL, Q4; SIITFEKL, T4; SIIVFEKL, V4; SIYNFEKL, Y3), then stained green and plated with untreated EL4 cells, in the same way as EL4-OVA cells were handled above. Small variations in antigen affinity did not result in significant changes in the efficiency of OT-I CD $8^{+} \mathrm{T}$ cell killing, with or without functional PI3K $\delta$ (Figure 2C) - even in EL4 cells presenting SIITFEKL (T4) peptide, which stimulated weaker proliferation than the A2, Q4, or Y3 peptides (13). SIIVFEKL (V4)-presenting EL4 cells were killed less effectively by WT OT-I T cells and not at all by PI3K $\delta^{\text {D910A }}$ OT-I T cells.

We previously reported that pharmacological inhibition of PI3K $\delta$ during the maturation phase of WT OT-I CD $8^{+} \mathrm{T}$ cells resulted in a defect in cytotoxicity equivalent to that seen in PI3K $\delta^{\mathrm{D} 910 \mathrm{~A}}$ cells (5). We therefore hypothesized that PI $3 \mathrm{~K} \delta^{\mathrm{D} 910 \mathrm{~A}} \mathrm{OT}-\mathrm{I} \mathrm{CD} 8^{+} \mathrm{T}$ cells might display an altered maturation profile after stimulation in vitro. WT and PI3K $\delta^{\mathrm{D} 910 \mathrm{~A}} \mathrm{OT}-\mathrm{I} \mathrm{CD} 8^{+} \mathrm{T}$ cells were cultured together with WT bone marrowderived dendritic cells pulsed with SIINFEKL peptide, and expression of activation markers measured at 24-hour intervals (Figure 2D). While WT OT-I CD8 ${ }^{+} \mathrm{T}$ cells rapidly downregulated CD62L expression upon stimulation, $\mathrm{PI} 3 \mathrm{~K} \delta^{\mathrm{D} 910 \mathrm{~A}}$ cells did not show a similar change, maintaining high levels of CD62L expression throughout the culture duration; this could represent an obstacle for the cells to exit lymphoid organs upon activation in vivo (14).

PI3K $\delta^{\text {D910A }}$ OT-I CD $8^{+} \mathrm{T}$ cells also expressed less granzyme A than their WT counterparts, while granzyme B expression was similar (Figure 2D). Reduced expression of granzymes A and B was observed in $\mathrm{PI} 3 \mathrm{~K} \delta^{\mathrm{D} 910 \mathrm{~A}}$ tumor-infiltrating $\mathrm{CD} 8^{+} \mathrm{T}$ cells from LLC-OVA and MC38-OVA tumors, respectively (Figure $2 \mathrm{E}$ ), showing that the defective maturation of $\mathrm{PI} 3 \mathrm{~K} \delta^{\mathrm{D} 910 \mathrm{~A}} \mathrm{CD} 8^{+} \mathrm{T}$ cells in vitro may be equally relevant in the tumor environment. However, the reduction of granzyme expression was variable and modest - intratumoral $\mathrm{CD} 8^{+} \mathrm{T}$ cells showed no difference in levels of granzyme A in MC38-OVA, or of granzyme B in LLC-OVA, or of either granzymes A or B in EL4-OVA.

Immunization with OVA-expressing L. monocytogenes revealed a reduced ability of PI3K $\delta^{D 910 A} C D 8^{+} T$ cells to respond to stimulation. As a measure of the $\mathrm{CD} 8^{+} \mathrm{T}$ cell response towards a tumor-specific antigen, OVAspecific $\mathrm{CD}^{+} \mathrm{T}$ cells from EL4-OVA, MC38-OVA, and LLC-OVA tumors were detected using the MHC class I:SIINFEKL oligomers (Figure 3A). EL4-OVA tumors had a relatively low proportion of $\mathrm{CD} 8^{+} \mathrm{T}$ cells within the tumor immune infiltrate, of which a small fraction $(\sim 5 \%)$ were specific for OVA. MC38OVA tumors contained a higher proportion of $\mathrm{CD} 8^{+} \mathrm{T}$ cells, but the OVA-specific response remained at a similarly low level to that induced by EL4-OVA tumors. LLC-OVA tumors were infiltrated with a relatively high proportion of $\mathrm{CD} 8^{+} \mathrm{T}$ cells. Most strikingly, approximately $30 \%$ of these infiltrating $\mathrm{CD} 8^{+} \mathrm{T}$ cells expressed a TCR specific for OVA (representative plots shown in Figure 3A). As was the case for the other tumor models, the fraction of OVA-specific $\mathrm{CD} 8^{+} \mathrm{T}$ cells within LLC-OVA tumors was not altered in PI3K $\delta$-deficient mice in comparison with WT.

To assess the ability of OVA-specific $\mathrm{CD} 8^{+} \mathrm{T}$ cells in these mice to mount a cytotoxic response against the OVA-expressing tumor, WT and PI3K $\delta^{\text {D910A }}$ mice bearing LLC-OVA tumors were immunized with attenuated L. monocytogenes - either expressing OVA (LM-OVA) or an irrelevant antigen YFP (LM-YFP) - 3 days after tumor implantation (Figure 3B). Blood was obtained from the mice 7 days after immunization, and assessed for the presence of anti-OVA response. WT mice mounted a strong $\mathrm{CD} 8^{+} \mathrm{T}$ cell response to LM-OVA, whereas in PI3K $\delta^{\mathrm{D} 910 \mathrm{~A}}$ mice this response was detectable but significantly reduced.

WT mice receiving the LM-OVA immunization showed a reduction in tumor growth compared with PI3K $\delta^{\text {D910A }}$ mice (Figure $3 \mathrm{C}$ ), accompanied by an increase in the fraction of OVA-specific CD8 ${ }^{+} \mathrm{T}$ cells within the tumor (Figure 3D). By contrast, LLC-OVA-bearing PI $3 \mathrm{~K} \delta^{\mathrm{D} 910 \mathrm{~A}}$ mice immunized with LMOVA showed no increase in tumor-infiltrating OVA-specific $\mathrm{CD} 8^{+}$cells. The protection of the WT mice 
A WT OT-I CD8 PI3Kס̄D910A OT-I CD8 No CD8
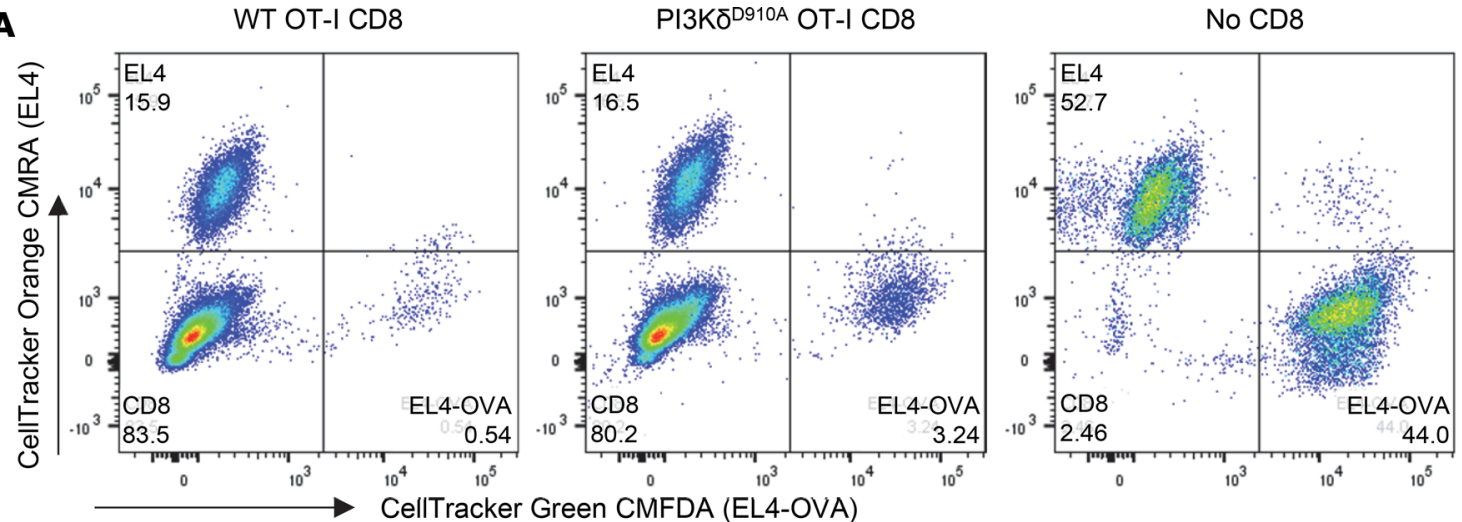

B

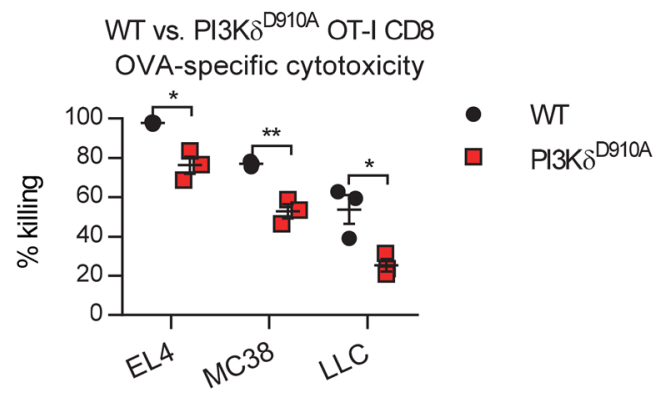

D
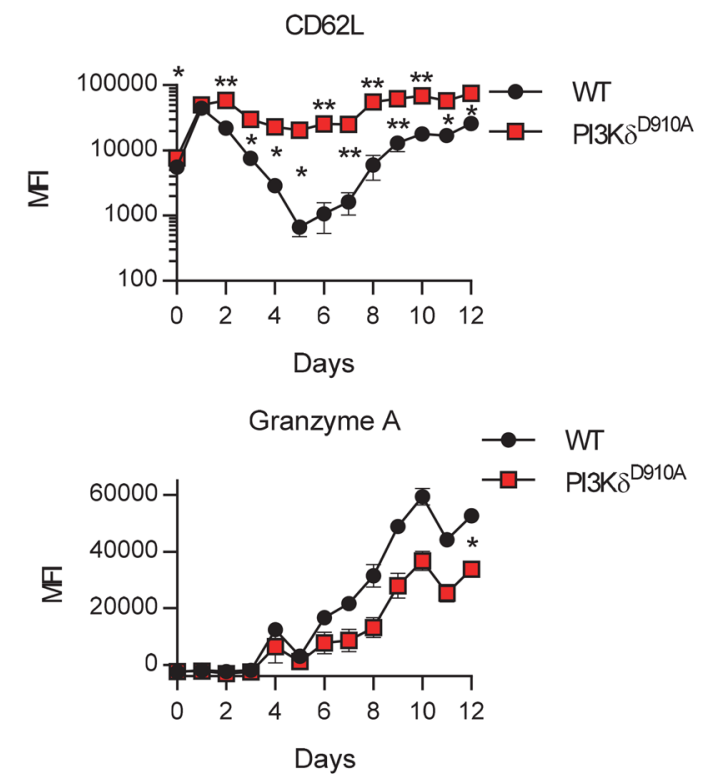

Granzyme B

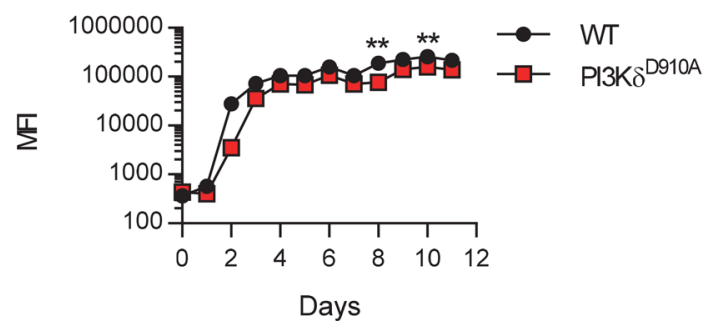

C WT vs. PI3K $\delta^{\mathrm{D} 910 \mathrm{~A}}$ OT-I CD8 cytotoxicity on cells presenting SIINFEKL peptide variants

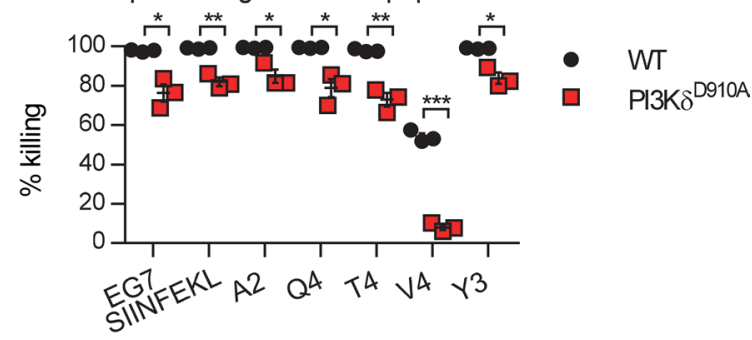

E

LLC-OVA
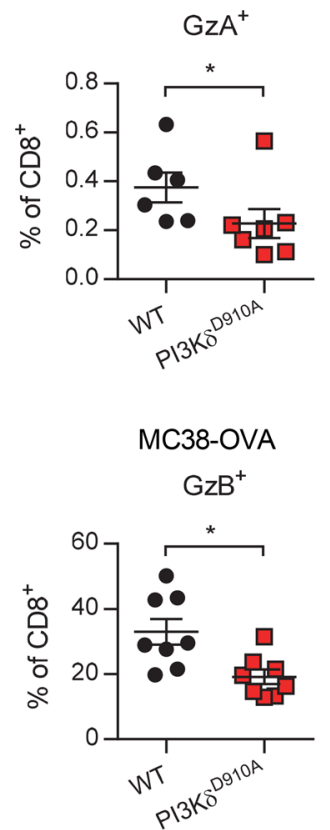

Figure 2. PI3K $\delta^{\mathrm{Dg} 10 \mathrm{~A}} \mathbf{C D 8}^{+} \mathbf{T}$ cells show functional defects. In vitro assays were conducted with 3 biological replicates. (A) CD8 ${ }^{+} \mathrm{T}$ cell cytotoxic capacity was measured in an in vitro killing assay, using tumor cells expressing ovalbumin (OVA) protein (stained with CMFDA CellTracker Green) as targets for in vitrostimulated OT-I CD8 ${ }^{+}$T cells, and parental tumor cells (stained with CMRA CellTracker Orange) as controls. Representative FACS plots shows EL4-OVA and 
EL4 cells incubated with, from left to right, WT, PI3K $\delta^{\mathrm{Dg10A}}$, or no CD8 ${ }^{+}$T cells. (B) Cytotoxic efficiency measured in WT versus PI3K $\delta^{\mathrm{D910A}}$ OT-I CD8 ${ }^{+}$cells using EL4-OVA, MC38-OVA, and LLC-OVA cells. (C) Cytotoxic efficiency measured in WT versus PI3K $\delta^{\text {D910A }}$ OT-I CD8 $8^{+}$cells using EL4 cells pulsed with SIINFEKL peptide, and single-amino-acid variants of decreasing binding affinity for the OT-I T cell receptor (TCR). (D) CD62L, granzyme A, and granzyme B expression measured in in vitro-stimulated WT versus PI3K $\delta^{\text {D910A }}$ OT-I CD8 $8^{+}$cells. MFI, median fluorescence intensity. (E) Granzyme $A$ and B expression measured in tumor-infiltrating CD8 ${ }^{+}$T cells from WT vs PI3K $\delta^{0910 A}$ mice $(n=8)$. Statistical significance was determined by multiple $t$ tests with Holm-Sidak correction (B-D) or the Mann-Whitney test (E). ${ }^{*} P<0.05 ;{ }^{* *} P<0.01$; ${ }^{* *} P<0.001$.

was OVA dependent, since mice that received LM-YFP did not show reduced tumor growth despite increased $\mathrm{CD} 8^{+} \mathrm{T}$ cell infiltration. These results reveal a defect in the ability of PI3K $\delta^{\mathrm{D} 910 \mathrm{~A}} \mathrm{CD} 8^{+} \mathrm{T}$ cells to respond to external stimuli that enhance antitumor responses, suggesting a more pronounced defect in $\mathrm{CD}^{+} \mathrm{T}$ cells than previously appreciated.

$P I 3 K \delta$ inactivation antagonized enhancement of Teff responses when combined with checkpoint blockade therapies. We hypothesized that the relief of tumor immunosuppression brought about by PI $3 \mathrm{~K} \delta$ inactivation could be fully exploited by strengthening the weakened $\mathrm{CD} 8^{+} \mathrm{T}$ cell response, using other established cancer immunotherapies in combination. Antibody therapies against CTLA-4, and against the PD-1/ PD-L1 signaling axis, are both in use in the clinic, having achieved remarkable success in the treatment of advanced melanoma (15-18). Both approaches aim to block the checkpoint signals that attenuate the function of activated Teffs, thus releasing Teffs from negative feedback control (19). PD-1/PD-L1 blockade has previously been shown to effectively reduce growth of EL4-OVA, MC38, and LLC tumors (20-22), while anti-CTLA-4 has not been as successful, at least as a monotherapy in tumors lacking expression of a strongly immunogenic antigen (23-25).

PI3K $\delta^{\mathrm{D} 910 \mathrm{~A}}$ mice were injected with either LLC-OVA or MC38-OVA tumors, and treated with 3 doses of antibody against CTLA-4 or PD-L1 (Figure 4A). Both tumor types were effectively treated with anti-CTLA-4 in WT mice, showing greatly reduced growth compared with mice treated with isotype control. In the absence of host PI3K $\delta$ activity, however, anti-CTLA-4 treatment had negligible effect on tumor growth (Figure 4, B and C). LLC-OVA tumors did not respond to anti-PD-L1 treatment, whether in WT or PI3K $\delta^{\mathrm{D} 910 \mathrm{~A}}$ mice (Figure 4D). In MC38-OVA tumors, a similar result was obtained with anti-PD-L1 antibody treatment as with anti-CTLA-4 - while tumor growth was restricted in WT mice, in PI $3 \mathrm{~K} \delta$-inactivated mice the antibody treatment failed to have a significant effect (Figure $4 \mathrm{E})$. The expression of a number of activation or functional markers was measured on $\mathrm{CD}^{+} \mathrm{T}$ cells and Tregs in MC38-OVA tumors, but we found no clear reason why PI3K $\delta^{\mathrm{D} 910 \mathrm{~A}} \mathrm{CD} 8^{+} \mathrm{T}$ cells should be impaired beyond rescue by combination therapy (Supplemental Figure 3). These results suggest that host PI3K $\delta$ function is required for the efficacy of anti-CTLA-4 and anti-PD-L1 treatment, and that $\mathrm{PI} 3 \mathrm{~K} \delta$ inactivation does not synergize with, but rather abrogates the antitumor effects achieved with the checkpoint blockade therapies.

\section{Discussion}

We have demonstrated that PI $3 \mathrm{~K} \delta$ inactivation attenuates Treg suppressive function, which can unleash a potent antitumor immune response, conditional upon the dependence of the specific tumor type on Treg immunosuppression. However, loss of $\mathrm{PI} 3 \mathrm{~K} \delta$ activity in $\mathrm{CD}^{+}$cells impairs the effector immune response, which can negate the beneficial effects of Treg dysfunction, and block the efficacy of checkpoint blockade therapies.

A striking observation that emerged early in this study was the complete independence of LLC-OVA tumors from Tregs to provide protection against immune attack, such that selective depletion of Tregs had no impact on tumor progression. This result strongly underscores the idea that the immune response to different tumors can be highly distinct, which dictates their response to each therapeutic strategy. LLC tumors are also known to derive immune suppression from cancer-associated fibroblasts (CAFs) (26). MC38 tumors have been found to be dependent on TAMs for immune evasion (27), suggesting redundancy between myeloid and Treg-mediated suppression.

Furthermore, the relative susceptibility of the EL4-OVA, MC38-OVA, and LLC-OVA cell lines to CD8 ${ }^{+}$ $\mathrm{T}$ cell cytotoxicity indicate cell-intrinsic differences, for example, in the ability to degrade granzyme B (28). While these differences may be difficult to translate directly to an in vivo setting, they may be important in explaining why the impaired cytotoxicity of $\mathrm{PI} 3 \mathrm{~K} \delta$-inactivated $\mathrm{CD} 8^{+} \mathrm{T}$ cells was still sufficient to eliminate EL4-OVA tumors in PI3K $\delta^{\mathrm{D} 910 \mathrm{~A}}$ mice, whereas this reduced $\mathrm{CD} 8^{+} \mathrm{T}$ cell function could not overcome even a compromised Treg suppression to kill MC38-OVA tumors. 
A

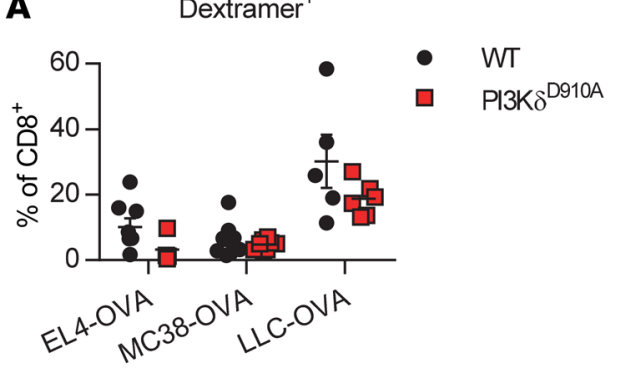

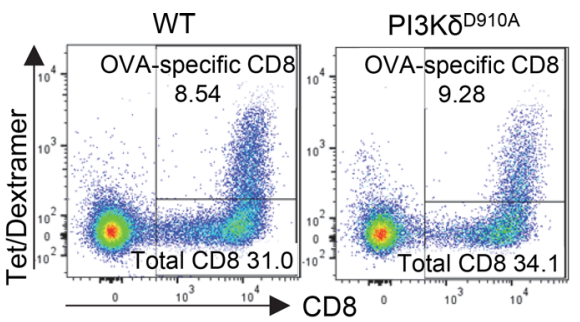

B

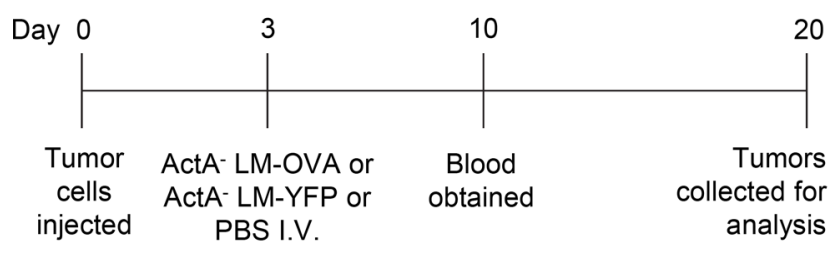

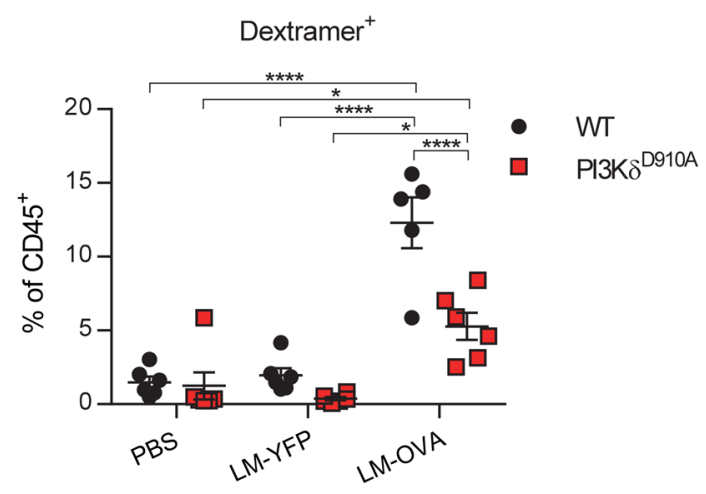

D

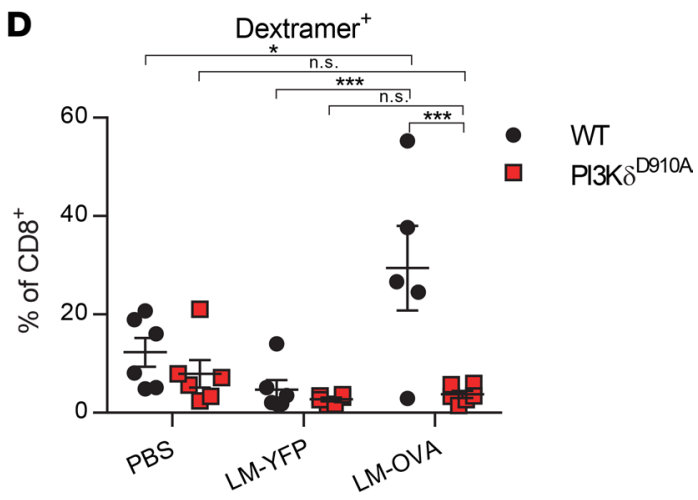

Figure 3. Defects in PI3Kס-deficient CD8 ${ }^{+} \mathbf{T}$ cell response abrogate antitumor effect of LM-OVA immunization. (A) OVA-specific CD8 $8^{+}$cell responses in the tumor immune infiltrate $(n=6)$. Representative plots show MHC class I:SIINFEKL dextramer staining on tumor-infiltrating CD8 ${ }^{+}$T cells in LLC-OVA tumors. Differences between WT and PI3K $\delta^{\text {D910A }}$ mice were not significant in all tumor types. (B) LLC-OVA tumor-bearing mice were immunized with attenuated LM-OVA or LM-YFP (both $10^{6} \mathrm{CFU}$ ) 3 days after tumor implantation. CD8 ${ }^{+} \mathrm{T}$ cell responses against the OVA antigen were measured in the blood 7 days after immunization $(n=6)$. (C) Tumor growth measured in WT and PI3K $\delta^{\text {D910A }}$ mice receiving PBS control, LM-YFP, or LM-OVA immunization $(n=12$, combined 2 experiments). (D) OVA-specific CD8 ${ }^{+}$T cell response in the tumor in response to immunization measured in WT and PI3K $\delta^{\mathrm{D} 910 \mathrm{~A}}$ mice $(n=6)$. Statistical significance determined by multiple $t$ tests with Holm-Sidak correction (A and C) or 2-way ANOVA with Tukey's multiple comparison (B and D). ${ }^{*} P<0.05$; ${ }^{* *} P<0.01$; ${ }^{* *} P<0.001$; ${ }^{* * *} P<0.0001$. n.s., not significant.

The effects of PI3K $\delta$ deficiency on effector immune cells have previously been discussed in several reports, with somewhat conflicting conclusions. Putz et al. found that PI3K $\delta^{-/-} \mathrm{CD} 8^{+} \mathrm{T}$ cells had defective expression of genes critical to cytotoxic function, and accordingly were impaired in their ability to eliminate tumor cells (29). We have also reported that PI3K $\delta$-inactivated mice have a reduced $\mathrm{CD}^{+} \mathrm{T}$ cell response to $L$. monocytogenes infection (30). On the other hand, it was recently reported that $\mathrm{PI} 3 \mathrm{~K} \delta$ inhibition selectively affected proliferation and viability in Tregs over conventional CD4 ${ }^{+} \mathrm{T}$ cells, thus conferring a therapeutic advantage in combination with a tumor peptide vaccine (31). The relative significance of $\mathrm{CD} 8^{+} \mathrm{T}$ cells and conventional $\mathrm{CD} 4^{+} \mathrm{T}$ cells in the antitumor response likely varies by tumor type, but we show here that a reduction in $\mathrm{CD}^{+} \mathrm{T}$ cell function is in some cases sufficient to abrogate the advantages of Treg impairment. This needs to be considered as PI $3 \mathrm{~K} \delta$ inhibitors are being developed for immunotherapy. 
A

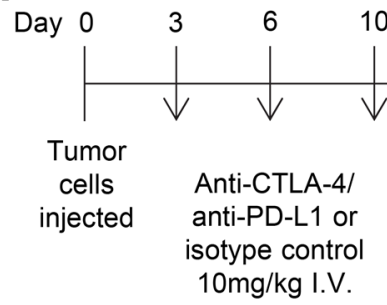

(LLC-OVA) 20

(MC38-OVA) 26

Tumors

collected for analysis
B LLC-OVA tumor mass

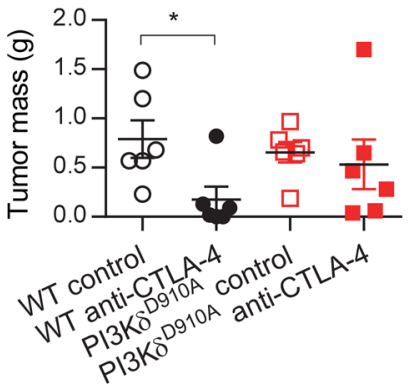

D LLC-OVA tumor mass

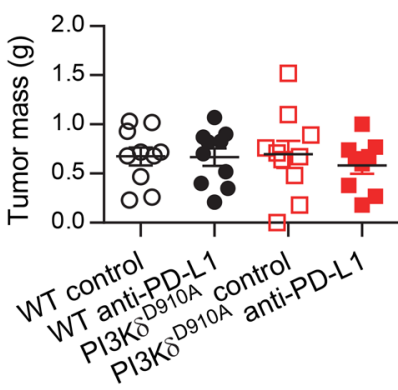

$\mathrm{CD}^{+}$

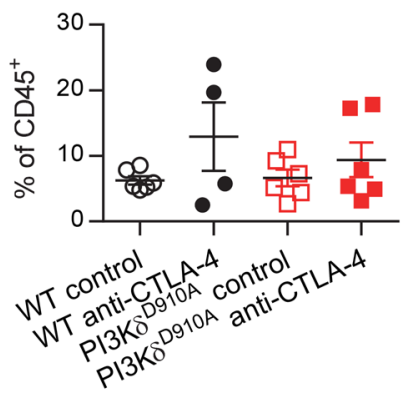

$\mathrm{CD}^{+}$

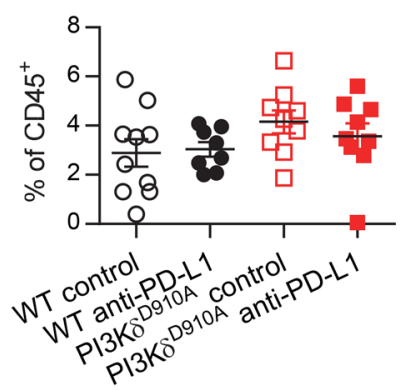

C MC38-OVA tumor mass

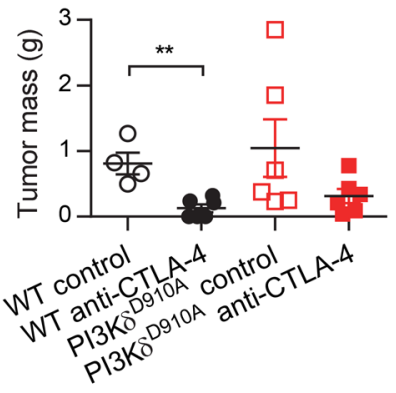

E

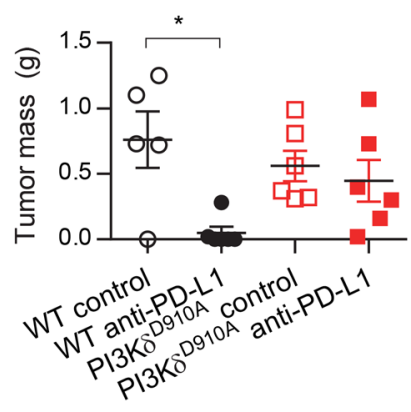

$\mathrm{CDB}^{+}$

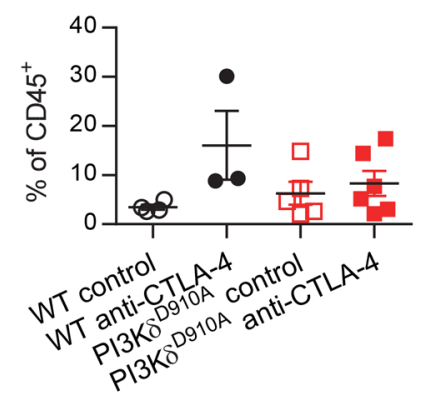

Figure 4. PI3K $\delta$-deficient CD8 ${ }^{+}$T cells fail to respond to checkpoint blockade. (A) Mice bearing LLC-OVA or MC38-OVA tumors received intravenous injections of antibodies against cytotoxic T lymphocyte antigen 4 (CTLA-4) or programmed death ligand 1 (PD-L1) on days 3, 6, and 10 after tumor injection (treatment of LLC-OVA tumor with anti-PD-L1 was performed on days 2, 5, and 9 after tumor injection) $(n=6)$. (B and C) Anti-CTLA-4 antibody treatment of LLC-OVA (B) and MC38-OVA (C) tumors in WT and PI3K $\delta^{\text {D910A }}$ mice; no significant change was observed in tumor-infiltrating CD8 ${ }^{+} T$ cells. ( $\mathbf{D}$ and $\mathbf{E})$ Anti-PD-L1 antibody treatment of LLC-OVA (D) and MC38-OVA (E) tumors in WT and PI3K $\delta^{\text {D910A }}$ mice. Only 2 WT tumors were available for analysis, and no significant changes were found in the $C D 8^{+}$infiltrate of these tumors. Statistical significance determined by Mann-Whitney test between antibody-treated and control groups. ${ }^{*} P<0.05 ;{ }^{* *} P<0.01$.

Where idelalisib is already administered as a treatment for CLL, reports of immune-mediated adverse events provide some insight to the effect of PI $3 \mathrm{~K} \delta$ inhibition on the human immune response (32). Both colitis and hepatotoxicity in idelalisib-treated patients are characterized by increased infiltration of $\mathrm{T}$ lymphocytes, suggesting an enhancement of the effector immune response $(33,34)$. Reductions in Treg numbers have not been consistently observed in these reports, but considering the imperfect correlation between numbers and function, as well as the upregulation of Foxp3 in human Teffs upon activation, the specific effects of PI3K $\delta$ inhibition on the human Treg response remain to be determined.

Our results highlight that the mechanism by which $\mathrm{PI} 3 \mathrm{~K} \delta$ inhibition leads to enhanced antitumor responses is distinct, and not necessarily complementary to that elicited using antibodies against CTLA-4 or PD-L1. Both of these therapies are intended to enhance the $\mathrm{CD}^{+} \mathrm{T}$ cell response, but were unable to enhance or compensate for the effects of PI3K $\delta$ inhibition. Mechanistically, checkpoint inhibitors may act in part by enhancing PI3K activity in Teffs. Hence, signaling through CTLA-4 antagonizes Akt activity through the type II serine/ threonine phosphatase PP2A, whereas PD-1 can activate SHP1 to inhibit CD28-dependent PI3K activity (3538). Thus, $\mathrm{PI} 3 \mathrm{~K} \delta$ inhibition may antagonize the signaling pathway unleashed by these checkpoint inhibitors. 
The antagonistic relationship between PI3K $\delta$ inhibition and checkpoint blockade does not necessarily preclude combining the 2 therapeutic modalities. Others have reported synergy in the treatment of MC38 tumors with a combination of a small-molecule PI3K $\delta$ inhibitor and anti-PD-1 (39), apparently in contrast with the results shown here. Administration of a PI3K $\delta$ inhibitor starting after the tumor becomes palpable may provide a crucial window of time for $\mathrm{CD} 8^{+} \mathrm{T}$ cells to encounter tumor antigens and become activated before PI3K $\delta$ signaling is shut down. We previously showed an important role for PI3K $\delta$ in the early phase of $\mathrm{CD}^{+} \mathrm{T}$ cell maturation, whereas it was no longer necessary for fully activated $\mathrm{CD} 8^{+} \mathrm{T}$ cells to kill target cells (5). Intermittent dosing with PI3K inhibitors, or dosing PI3K inhibitors sequentially with immune checkpoint inhibitors, may be strategies worth considering. In fact, the inhibition of PI3K $\delta$ during the in vitro expansion of $\mathrm{T}$ cells subsequently used for adoptive cell therapy enhances tumor rejection in mice, potentially by expanding a subset of $\mathrm{CD}^{+} \mathrm{T}$ cells with stem cell-like properties that may allow for a more persistent attack on the tumors (40-42). The challenge therefore will be to harness this potential to enhance the durability of the $\mathrm{CD} 8^{+} \mathrm{T}$ cell response while inhibiting Treg-mediated suppression. Our accompanying report (27) suggests that rather than combining PI3K $\delta$ inhibitors with agents that boost $\mathrm{T}$ cell costimulation, combinatorial targeting of suppressive cell populations, such as using PI3K $\delta$ inhibitors to target Treg and CSF-1 inhibitors to target suppressive monocytes may be a better strategy, taking advantage of the multiple immune-suppressive mechanisms employed by cancers.

\section{Methods}

Mice. C57BL/6.Babr and B6.SJL.Babr (WT) mice were obtained from the breeding colonies in the Biological Services Unit, Babraham Institute. All other mice used in this study were maintained on a C57BL/6 background. p110 $\delta^{\mathrm{D} 910 \mathrm{~A} / \mathrm{D} 910 \mathrm{~A}}\left(\mathrm{PI} 3 \mathrm{~K} \delta^{\mathrm{D} 910 \mathrm{~A}}\right)$ mice have an aspartic acid-to-alanine (D910A) point mutation in the p110 catalytic domain, rendering it inactive (43). OT-I mice express a transgenic TCR (V $\alpha 2-\mathrm{V} \beta 5)$ specific for the OVA peptide SIINFEKL (OVA 257-264) presented by MHC class IA (H-2Kb) (44), and homogeneously express CD45.1. The OT-I transgenic TCR was crossed to a PI3K $\delta$-inactivated background, in the PI3K $\delta^{\mathrm{D} 910 \mathrm{~A}} \times$ OT-I strain. Foxp3-YFP-Cre $(\mathrm{FYC})$ mice express a YFP-Cre fusion protein reporter in Foxp3-expressing cells (45). These mice were crossed with a mouse strain harboring $\operatorname{lox} P$ sites flanking alleles $1-9$ of the Pik3cd gene, such that p110 $\delta$ was specifically deleted in Foxp $3^{+}$cells (FYC $\times$ p1108 $\delta^{\mathrm{f} / \mathrm{fl}}$ strain) (5). Foxp3 $3^{\mathrm{DTR}}$ mice express the human DTx receptor and an eGFP reporter under the Foxp3 promoter, allowing specific depletion of Foxp3 ${ }^{+}$cells upon administration of DTx (46).

All mice were maintained under specific pathogen-free conditions in the Biological Services Unit, Babraham Institute. Mice were matched for age (8-14 weeks) and sex (balanced) in each experiment. Studies involving administration of treatment substances were blinded for tumor growth measurement. Where applicable, experimental group sizes are indicated by individual data points.

Tumors. EL4 and EL4-OVA (also known as EG7) cells were obtained from ATCC (47, 48). LLC cells were obtained from Douglas Fearon (Cancer Research UK Cambridge Institute, Cambridge, United Kingdom) along with the LLC-OVA derivative (26). MC38 and MC38-OVA cell lines were obtained from from Mark Smyth (QIMR Berghofer, Brisbane, Australia) $(49,50)$. Cells were maintained in culture in DMEM with high glucose and L-glutamine (GIBCO) containing 10\% FCS (LabTech); EL4-OVA cultures were supplemented with $400 \mu \mathrm{g} / \mathrm{ml}$ G418 selection antibiotic (Melford Laboratories Ltd) from 48 hours after thawing. The adherent cell lines (LLC, LLC-OVA, MC38, and MC38-OVA) were dissociated from culture flasks using Cell Dissociation Buffer (GIBCO).

Suspensions of tumor cells were prepared in sterile PBS (in-house preparation). EL4-OVA or LLCOVA cells $\left(5 \times 10^{5} \mathrm{each}\right)$, or $2 \times 10^{6} \mathrm{MC} 38$-OVA cells, were administered by subcutaneous injection under inhaled anesthesia (isoflurane). When tumors became palpable (around day 8 after implantation for EL4-OVA tumors, or around day 10 for LLC-OVA and MC38-OVA tumors), tumor growth was monitored by caliper measurements every 2-3 days. Tumor volume $\left(\mathrm{mm}^{3}\right)$ was calculated as length $\times$ width $^{2}$. Mice bearing EL4-OVA tumors were culled between 16 and 17 days after implantation, mice bearing LLC-OVA tumors between 20 and 22 days, and mice bearing MC38-OVA tumors between 24 and 28 days; where experimental schedules depart from this schedule (e.g., in cases of unexpectedly aggressive tumor growth) this is indicated in the relevant figure legend. Any mice bearing tumors that approached or exceeded the terminal size limit during the course of the study were culled and excluded from the study. A maximum of $1 \mathrm{~g}$ of tumor tissue per sample was processed on a gentleMACS Dissociator (Miltenyi Biotec) according to the 'soft/medium tissue' protocol from the Tumor Dissociation 
Kit (mouse) (Miltenyi Biotec). Any tumors that did not yield sufficient cells for robust quantification was excluded from cellular-level analysis.

Depletion of Tregs with DTx. DTx from Corynebacterium diphtheriae (Sigma-Aldrich) was obtained in lyophilized powder form, and reconstituted in $0.5 \mathrm{ml}$ sterile double-distilled water according to the manufacturer's instructions. Solutions for injection were made up in sterile PBS to a dose of $25 \mu \mathrm{g} / \mathrm{kg}$, separately calculated based on average weights of male and female mice in each cohort. To achieve transient depletion of Tregs in Foxp3 $3^{\text {DTR }}$ mice, DTx was administered to the peritoneum in $100 \mu 1$, with mice under inhaled anesthesia, on days 3, 7, and 10 after tumor implantation.

Flow cytometry. Fluorochrome-conjugated antibodies against CD45 (clone 30-F11), CD4 (clone RM4-5), CD8 (clone 53-6.7), CD62L (clone MEL-14), and granzyme A (clone CBA) were purchased from Biolegend. Anti-Foxp3 (clone FJK-16s) was purchased from eBioscience, and anti-granzyme B (clone GB11) was purchased from Invitrogen. Surface stains were carried out in PBS containing 2\% FCS for 30 minutes at $4^{\circ} \mathrm{C}$, with the exception of assays including the MHC class I:SIINFEKL tetramer (MBL) or dextramer (Immudex) (30 minutes at room temperature). Fixation and permeabilization for intracellular staining was carried out with the Foxp3/Transcription Factor Staining Buffer set (eBioscience), with a 15-minute fixation at room temperature, followed by intracellular staining in permeabilization buffer for 30 minutes at $4^{\circ} \mathrm{C}$.

In assays with unfixed cells, DAPI (4',6-diamidine-2'-phenylindole dihydrochloride, Sigma-Aldrich) was added to samples at $1 \mu \mathrm{g} / \mathrm{ml}$ prior to analysis on the flow cytometer. In assays where cells are fixed, Fixable Viability Dye eFluor 780 (eBioscience) was added to the surface stain solution at a 1:3,000 dilution. Samples were acquired on BD Fortessa analyzers in the Babraham Institute Flow Core Facility. Data collected were analyzed using FlowJo software (Tree Star).

In vitro cytotoxicity assay. Splenocytes from OT-I and PI3K $\delta^{\mathrm{D} 910 \mathrm{~A}} \times$ OT-I mice $(n=3$ for each group) were stimulated with SIINFEKL peptide at $10 \mathrm{nM}$. After 48 hours, $\mathrm{CD} 8^{+} \mathrm{T}$ cells were isolated from the cultures by MACS negative selection (Miltenyi Biotec). The $\mathrm{CD} 8^{+} \mathrm{T}$ cells were returned to culture with daily supplement of recombinant human IL-2 (Glaxo-IMB), at a concentration of $20 \mathrm{ng} / \mathrm{ml}$, for an additional 6 days. Parental tumor cells and OVA-expressing derivatives were stained with, respectively, CellTracker Orange CMRA and CellTracker Green CMFDA (Molecular Probes). Peptide-presenting EL4 cells were incubated with the OVA oligopeptide SIINFEKL, and 5 single-amino-acid variants - SAINFEKL, SIIQFEKL, SIITFEKL, SIIVFEKL, and SIYNFEKL (ProImmune ThinkPeptides) - at $10 \mathrm{nM}$ for 1 hour. Each parental/OVA-expressing derivative pair (EL4 and EL4-OVA, LLC and LLC-OVA, and MC38 and MC38-OVA) (10 cells each), and $10^{5}$ in vitro-activated $\mathrm{CD}^{+} \mathrm{T}$ cells were incubated together, giving a 1:1:10 mixture of orange-stained cells (parental), green-stained cells (OVA-expressing), and CD8 ${ }^{+} \mathrm{T}$ cells.

After 18 hours, the cells were resuspended in Cell Dissociation Buffer (GIBCO) containing $1 \mu \mathrm{g} / \mathrm{ml}$ DAPI. Once dissociated, samples were acquired on the Fortessa flow cytometer (Beckton Dickinson), recording CMRA on the 585/15 $561 \mathrm{~nm}$ channel, CMFDA on 530/30 488 nm, and DAPI on 450/50 405 $\mathrm{nm}$. Cytotoxic efficiency was calculated as a ratio of live (DAPI-), OVA-expressing cells (antigen-presenting target cells, green) over parental cells, which did not express the OT-I CD ${ }^{+}$target antigen (orange), normalized to ratios recorded in wells to which no $\mathrm{CD} 8^{+} \mathrm{T}$ cells were added.

In vitro $C D 8^{+}$maturation assay. $\mathrm{CD}^{+} \mathrm{T}$ cells were isolated from spleens and lymph nodes of $\mathrm{WT}$ and PI3K $\delta^{\text {D910A }}$ OT-I mice by MACS negative selection, and cultured together with WT bone marrow-derived dendritic cells that had been pulsed with 100 pM SIINFEKL peptide for 2 hours, at a 5:1 ratio. Cultures were maintained at approximately $3 \times 10^{6} \mathrm{cells} / \mathrm{ml}$ and supplemented with $20 \mathrm{ng} / \mathrm{ml}$ recombinant human IL-2 (Glaxo-IMB) daily from 48 hours onwards. Aliquots were taken at 24-hour intervals for flow analysis.

Vaccination with attenuated OVA-expressing L. monocytogenes. Tumor-bearing mice were inoculated with attenuated (ActA $\left.{ }^{-}\right)$LM-OVA to induce a $C D 8^{+} \mathrm{T}$ cell immune response to OVA, also expressed in tumor cells. The original stocks of attenuated LM-OVA, as well as a strain of LM expressing an irrelevant antigen (attenuated LM-YFP) were obtained from Hao Shen (University of Pennsylvania, Philadelphia, Pennsylvania, USA) (51). LM-OVA and LM-YFP (106 CFU per mouse) were administered intravenously in $100 \mu 1,3$ days after tumor implantation, with attenuated LM-YFP as a control for non-antigen-specific immunization, and with PBS as a negative control. Samples of blood $(50 \mu \mathrm{l})$ were obtained from each mouse at 7 days after inoculation, to confirm the presence of a $\mathrm{CD}^{+} \mathrm{T}$ cell response against OVA.

Checkpoint blockade treatment. WT and PI3K $\delta^{\mathrm{D} 910 \mathrm{~A}}$ tumor-bearing mice were treated with anti-CTLA4 antibody (clone 9H10, Bio X Cell) and anti-PD-L1 antibody (clone 10F.9G2, Bio X Cell). The isotype controls used in these experiments were, respectively, polyclonal Syrian hamster IgG (Bio X Cell), and rat 
IgG2b (clone LTF-2, Bio X Cell) at a dose of $10 \mathrm{mg} / \mathrm{kg}$, in a volume of $100 \mu \mathrm{l}$, separately calculated based on average weights of male and female mice in each cohort, on days 3, 6, and 10 after tumor implantation (administered by technicians in the Babraham Institute Biological Support Unit); where experimental schedules depart from this schedule this is indicated in the relevant figure legend.

Statistics. Statistical analyses of results were carried out using GraphPad Prism. Unless otherwise specified, the Mann-Whitney (2-tailed nonparametric $t$ ) test or multiple $t$ tests (with Holm-Sidak correction for multiple comparison) was applied to assess significance, with $P<0.05$ considered significant. Error bars presented in plots represent standard error of the mean (SEM). Any repeats of experiments are indicated in figure legends. ${ }^{*} P<0.05 ;{ }^{* *} P<0.01 ;{ }^{* * *} P<0.001 ;{ }^{* * * *} P<0.0001$.

Study approval. All protocols involving live animals were approved by the United Kingdom Home Office (PPL 70/7661) and Babraham Institute Animal Welfare and Ethics Review Board.

\section{Author contributions}

Experiments were performed by ELL, with contributions from FMC, DRR, and DG. RR and KO supervised the study. ELL and KO wrote the manuscript.

\section{Acknowledgments}

We are grateful for the expert assistance provided by Rachael Walker and Arthur Davis at the Flow Cytometry facility, and for the technical support from staff at the Biological Services Unit. E.L. Lim was supported by the Yousef Jameel Scholarship (Cambridge Trust). D. Gyori was funded by a grant from Karus Therapeutics Ltd. R. Roychoudhuri and K. Okkenhaug received institute support from Biotechnology and Biological Sciences Research Council (BBSRC) BBS/E/B/000C0407, -C0409, -C0427, and -C0428 and project grant BB/N007794/1. R. Roychoudhuri was supported by Wellcome Trust grant 105663/Z/14/Z . K. Okkenhaug was also supported by Wellcome Trust grant 095198/Z/10/Z.

Address correspondence to: Klaus Okkenhaug, Department of Pathology, University of Cambridge, Tennis Court Road, Cambridge, CB2 1QP, United Kingdom. Phone: 44.1223.333726; Email: ko256@cam.ac.uk.

ELL's present address is: Immunology Frontier Research Center, Osaka University, Osaka, Japan.

1. Dong H, et al. Tumor-associated B7-H1 promotes T-cell apoptosis: a potential mechanism of immune evasion. Nat Med 2002;8(8):793-800.

2. Maker AV, Attia P, Rosenberg SA. Analysis of the cellular mechanism of antitumor responses and autoimmunity in patients treated with CTLA-4 blockade. J Immunol. 2005;175(11):7746-7754.

3. Curran MA, Montalvo W, Yagita H, Allison JP. PD-1 and CTLA-4 combination blockade expands infiltrating T cells and reduces regulatory T and myeloid cells within B16 melanoma tumors. Proc Natl Acad Sci USA. 2010;107(9):4275-4280.

4. Simpson TR, et al. Fc-dependent depletion of tumor-infiltrating regulatory T cells co-defines the efficacy of anti-CTLA-4 therapy against melanoma. J Exp Med. 2013;210(9):1695-1710.

5. Ali K, et al. Inactivation of PI(3)K p1108 breaks regulatory T-cell-mediated immune tolerance to cancer. Nature. 2014;510(7505):407-411.

6. Okkenhaug K, Vanhaesebroeck B. PI3K in lymphocyte development, differentiation and activation. Nat Rev Immunol. 2003;3(4):317-330.

7. Okkenhaug K. Signaling by the phosphoinositide 3-kinase family in immune cells. Annu Rev Immunol. 2013;31:675-704.

8. Furman RR, et al. Idelalisib and rituximab in relapsed chronic lymphocytic leukemia. N Engl J Med. 2014;370(11):997-1007.

9. Gopal AK, et al. PI3K $\delta$ inhibition by idelalisib in patients with relapsed indolent lymphoma. N Engl J Med. 2014;370(11):1008-1018.

10. Okkenhaug K, Graupera M, Vanhaesebroeck B. Targeting PI3K in cancer: Impact on tumor cells, their protective stroma, angiogenesis, and immunotherapy. Cancer Discov. 2016;6(10):1090-1105.

11. Fruman DA, Chiu H, Hopkins BD, Bagrodia S, Cantley LC, Abraham RT. The PI3K pathway in human disease. Cell. 2017;170(4):605-635.

12. Pierson W, et al. Antiapoptotic Mcl-1 is critical for the survival and niche-filling capacity of Foxp3+ regulatory T cells. Nat Immunol. 2013;14(9):959-965.

13. Zehn D, Lee SY, Bevan MJ. Complete but curtailed T-cell response to very low-affinity antigen. Nature. 2009;458(7235):211-214.

14. Finlay DK, et al. PDK1 regulation of $\mathrm{mTOR}$ and hypoxia-inducible factor 1 integrate metabolism and migration of $\mathrm{CD} 8^{+} \mathrm{T}$ cells. J Exp Med. 2012;209(13):2441-2453.

15. Hodi FS, et al. Improved survival with ipilimumab in patients with metastatic melanoma. N Engl J Med. 2010;363(8):711-723.

16. Wolchok JD, et al. Nivolumab plus ipilimumab in advanced melanoma. N Engl J Med. 2013;369(2):122-133.

17. Robert C, et al. Pembrolizumab versus ipilimumab in advanced melanoma. N Engl J Med. 2015;372(26):2521-2532.

18. Weber JS, et al. Nivolumab versus chemotherapy in patients with advanced melanoma who progressed after anti-CTLA-4 treatment (CheckMate 037): a randomised, controlled, open-label, phase 3 trial. Lancet Oncol. 2015;16(4):375-384. 
19. Topalian SL, Drake CG, Pardoll DM. Immune checkpoint blockade: a common denominator approach to cancer therapy. Cancer Cell. 2015;27(4):450-461.

20. Taylor A, Rothstein D, Rudd CE. Small-molecule inhibition of PD-1 transcription is an effective alternative to antibody blockade in cancer therapy. Cancer Res. 2018;78(3):706-717.

21. Homet Moreno B, et al. Response to programmed cell death-1 blockade in a murine melanoma syngeneic model requires costimulation, CD4, and CD8 T cells. Cancer Immunol Res. 2016;4(10):845-857.

22. Nagato T, Lee YR, Harabuchi Y, Celis E. Combinatorial immunotherapy of polyinosinic-polycytidylic acid and blockade of programmed death-ligand 1 induce effective CD8 T-cell responses against established tumors. Clin Cancer Res. 2014;20(5):1223-1234.

23. Met $\mathrm{O}$, Wang M, Pedersen AE, Nissen MH, Buus S, Claesson MH. The effect of a therapeutic dendritic cell-based cancer vaccination depends on the blockage of CTLA-4 signaling. Cancer Lett. 2006;231(2):247-256.

24. Kocak E, et al. Combination therapy with anti-CTL antigen-4 and anti-4-1BB antibodies enhances cancer immunity and reduces autoimmunity. Cancer Res. 2006;66(14):7276-7284.

25. Lesterhuis WJ, et al. Synergistic effect of CTLA-4 blockade and cancer chemotherapy in the induction of anti-tumor immunity. PLoS One. 2013;8(4):e61895

26. Kraman M, et al. Suppression of antitumor immunity by stromal cells expressing fibroblast activation protein-alpha. Science. 2010;330(6005):827-830.

27. Gyori $\mathrm{D}$, et al. Compensation between $\mathrm{CSF} 1 \mathrm{R}^{+}$macrophages and Foxp $3^{+}$Treg cells drives resistance to tumor immunotherapy. JCI Insight. 2018;3(11):e120631.

28. Baginska J, et al. Granzyme B degradation by autophagy decreases tumor cell susceptibility to natural killer-mediated lysis under hypoxia. Proc Natl Acad Sci USA. 2013;110(43):17450-17455.

29. Putz EM, et al. PI3K $\delta$ is essential for tumor clearance mediated by cytotoxic T lymphocytes. PLoS One. 2012;7(7):e40852.

30. Pearce VQ, Bouabe H, MacQueen AR, Carbonaro V, Okkenhaug K. PI3K $\delta$ Regulates the magnitude of CD $8^{+} \mathrm{T}$ cell responses after challenge with Listeria monocytogenes. J Immunol. 2015;195(7):3206-3217.

31. Ahmad S, et al. Differential PI3K $\delta$ signaling in $\mathrm{CD}^{+} \mathrm{T}$-cell subsets enables selective targeting of T regulatory cells to enhance cancer immunotherapy. Cancer Res. 2017;77(8):1892-1904.

32. Greenwell IB, Ip A, Cohen JB. PI3K inhibitors: Understanding toxicity mechanisms and management. Oncology (Williston Park, NY). 2017;31(11):821-828

33. Lampson BL, et al. Idelalisib given front-line for treatment of chronic lymphocytic leukemia causes frequent immune-mediated hepatotoxicity. Blood. 2016;128(2):195-203

34. Yeung CC ,et al. Pathological assessment of gastrointestinal biopsies from patients with idelalisib-associated diarrhea colitis [published online ahead of print March 28, 2018]. Future Oncol. https://doi.org/10.2217/fon-2017-0528.

35. Parry RV, et al. CTLA-4 and PD-1 receptors inhibit T-cell activation by distinct mechanisms. Mol Cell Biol. 2005;25(21):9543-9553.

36. Patsoukis N, Li L, Sari D, Petkova V, Boussiotis VA. PD-1 increases PTEN phosphatase activity while decreasing PTEN protein stability by inhibiting casein kinase 2. Mol Cell Biol. 2013;33(16):3091-3098.

37. Hui E, et al. T cell costimulatory receptor CD28 is a primary target for PD-1-mediated inhibition. Science. 2017;355(6332):1428-1433.

38. Kamphorst AO, et al. Rescue of exhausted CD8 T cells by PD-1-targeted therapies is CD28-dependent. Science. 2017;355(6332):1423-1427.

39. Koblish HK, et al. Abstract C103: The combination of PI3k $\delta$-selective inhibition and immunomodulation shows efficacy in solid tumor models. Mol Cancer Ther. 2015;14(12 Supplement 2):C103-C103.

40. Crompton JG, et al. Akt inhibition enhances expansion of potent tumor-specific lymphocytes with memory cell characteristics. Cancer Res. 2015;75(2):296-305.

41. Bowers JS, et al. PI3K $\delta$ inhibition enhances the antitumor fitness of adoptively transferred CD8 ${ }^{+}$T cells. Front Immunol. 2017;8:1221.

42. Abu Eid R, et al. Enhanced therapeutic efficacy and memory of tumor-specific CD8 T cells by ex vivo PI3K- $\delta$ inhibition. Cancer Res. 2017;77(15):4135-4145.

43. Okkenhaug $\mathrm{K}$, et al. Impaired $\mathrm{B}$ and $\mathrm{T}$ cell antigen receptor signaling in p110delta PI 3-kinase mutant mice. Science. 2002;297(5583):1031-1034.

44. Hogquist KA, Jameson SC, Heath WR, Howard JL, Bevan MJ, Carbone FR. Pillars article: T cell receptor antagonist peptides induce positive selection. Cell. 1994. 76: 17-27. J Immunol. 2012;188(5):2046-2056.

45. Rubtsov YP, et al. Regulatory T cell-derived interleukin-10 limits inflammation at environmental interfaces. Immunity. 2008;28(4):546-558.

46. Kim JM, Rasmussen JP, Rudensky AY. Regulatory T cells prevent catastrophic autoimmunity throughout the lifespan of mice. Nat Immunol. 2007;8(2):191-197.

47. Gorer PA. Studies in antibody response of mice to tumour inoculation. Br J Cancer. 1950;4(4):372-379.

48. Moore MW, Carbone FR, Bevan MJ. Introduction of soluble protein into the class I pathway of antigen processing and presentation. Cell. 1988;54(6):777-785.

49. Corbett TH, Griswold DP, Roberts BJ, Peckham JC, Schabel FM. Tumor induction relationships in development of transplantable cancers of the colon in mice for chemotherapy assays, with a note on carcinogen structure. Cancer Res. 1975;35(9):2434-2439.

50. Gilfillan S, et al. DNAM-1 promotes activation of cytotoxic lymphocytes by nonprofessional antigen-presenting cells and tumors. J Exp Med. 2008;205(13):2965-2973

51. Pearce EL, Shen H. Generation of CD8 T cell memory is regulated by IL-12. J Immunol. 2007;179(4):2074-2081. 